\title{
Determination of protective properties of Bardejovske Kupele spa curative waters by rotational viscometry and ABTS assay
}

\author{
Dominika Topolska ${ }^{1}$, Katarina Valachova ${ }^{1}$, Eva Hrabarova $^{2}$, Peter Rapta $^{3}$, Maria Banasova $^{l}$, \\ Ivo Juranek ${ }^{1}$, Ladislav Soltes ${ }^{1}$ \\ ${ }^{1}$ Institute of Experimental Pharmacology and Toxicology, Slovak Academy of Sciences, SK-84104 Bratislava, Slovak Republic, \\ ${ }^{2}$ Department of Carbohydrate Enzymology, Institute of Chemistry, Slovak Academy of Sciences, SK-84104 Bratislava, Slovak Republic, \\ ${ }^{3}$ Institute of Physical Chemistry and Chemical Physics, Faculty of Chemical and Food Technology, Slovak University of Technology, SK- \\ 81237 Bratislava, Slovak Republic
}

\begin{abstract}
Mineral waters from Bardejovske Kupele spa are natural, strongly mineralized, with healing effects. They are classified as hydrocarbonic - containing chloride and sodium - carbonic, cold, hypotonic, with a relatively high boric acid content. Potential anti-oxidative effects of curative waters from Bardejovske Kupele were investigated against the hyaluronan (HA) degradation. High-molar-mass HA was exposed to the action of ascorbate and cupric ions, which initiate free-radical chain degradation. Time-dependent changes of dynamic viscosity $(\eta)$ of the HA solutions were monitored by rotational viscometry. The radical scavenging capacity of curative waters was determined by the ABTS assay. Despite a significantly high content of transition metal ions, especially iron, remarkable protective effects of the two curative spa waters were found, namely Alzbeta and Klara. Even though "Alzbeta's" iron content was 3.5-fold higher than "Klara's", "Alzbeta" was shown to have better protective properties against the HA degradation compared to "Klara". Bolus addition of ferric ions to the reaction system instead of the natural iron-containing curative water caused a significant HA degradation. The ABTS decolorization assay revealed that the curative spa waters were proven as poorly effective scavengers of the $\mathrm{ABTS}^{\circ+}$ cation radical.
\end{abstract}

Keywords: ABTS assay, curative spa waters, hyaluronan, rotational viscometry

Abbreviations: ABTS - 2,2'-azinobis(3-ethylbenzothiazoline-6-sulfonic acid; HA - hyaluronan; $\eta$ - dynamic viscosity ROS - reactive oxygen species; RNS - reactive nitrogen species

\section{Introduction}

Beautiful and abundant natural ecosystem offers to mankind lots of excellent therapeutic bioresources among which mineral waters have been, particularly, known for their curative effects since ancient times. This fact had been a positive signal for our ascendants in the past to later utilization of natural open-bathings generally named spa - for remedies of their health inconveniences.

There are more possible explanations of the origin of a word "spa". It can be originated from the Walloon word "espa" (fountain). This word may also be derived from the Latin word "spagere", meaning to scatter, sprinkle, moisten or may also come from a Latin phrase "sanitas per aquas" which means "health through water".
Due to the increasing amount of people going to diverse spas for health, wellness and relaxation, spa-going has been described as a new cultural trend. But, in fact, spa-going within the meaning of social bathing in "healing waters" has been practiced for thousands of years.

Ancient Greek bathing (11th century BC to 7th century BC) served just for cleaning and hygienic purposes. It changed at the time of Hippocrates (460-370 BC) when healthy and beneficial properties of bathing for most diseases came forth. General treatments such as hydrotherapy and drinking cures were introduced at 1st-2nd century by Asclepiades, a Greek physician. Asclepiades suggested bathing for therapeutic as well as preventive purposes. Gaius Plinius Secundus (AD 23-79) 
determined different properties and indications for healing in different types of waters.

During the Roman Empire, military forces were often the key subjects in point of the spa development. The rise of Christianity and the fall of the Roman Empire in the year 476 resulted in prohibition of bathing. By the turn of the 17th century, many spas were rediscovered and bathing became again popular (van Tubergen and van der Linden, 2002).

Mineral waters can be generally classified according to the chemical-physical analyses (temperature, density, $\mathrm{pH}$, radioactivity, etc.), the chemical analyses (dry residues, ozone, sulphydrometric grade, gasses dissolved), the general characteristics (colour, taste, limpidity, etc.), the total salt content in grams after evaporation of 1-litre mineral water dried at $180^{\circ} \mathrm{C}$ (dry residues) (Albertini and Dachà, 2007).

Just few spas can offer such a combination of unique climate, convenient location, beautiful natural scenery and natural healing resources with exceptional composition as Bardejovske Kupele Inc. can. This spa can provide its visitors all benefits of therapeutic conditions offered by the surrounding nature, and are therefore ideal for both therapeutic and relaxation stays. Ten spring sources rise from a relatively small zone in the inner spa area. Spa mineral waters of Bardejovske Kupele and diseases treated by these waters are summed in Table 1. The spa waters are natural, strongly mineralized, with healing effects. They are bicarbonated, salted, ferruginous, cold, hypotonic with an increased content of boric acid (Table 1). The total mineralization ranges from 1,600 mg/L ("Klara") to $9,400 \mathrm{mg} / \mathrm{L}$ ("Herkules"), and that of carbonic oxide from $2,200 \mathrm{mg} / \mathrm{L}$ to $3,800 \mathrm{mg} / \mathrm{L}$. Number of elements in the water is different in each of the source, and therefore the ordinary therapeutic doses are determined by physicians and depend on indications and the health status of clients. Waters are mainly used for drinking cures, mineral baths and inhalation (http://www.balneotherma.sk/sk/pobyty/bardejov.html).

Hyaluronan (HA) is a linear highmolar-mass natural polysaccharide composed of $\mathrm{N}$-acetyl-D-glucosamine and D-glucuronic acid linked by $\beta-(1 \rightarrow 4)$ and $\beta-(1 \rightarrow 3)$ linkages. Molar mass of the HA biopolymer ranges from hundreds of thousands up to several millions of daltons. Physico-chemical and biological properties of HA have been shown to be molar mass-dependent. While high-molar-mass HA possesses anti-angiogenic, anti-inflammatory, and immunosuppressive properties, intermediate and low-sized HA fragments act predominantly in an opposite manner, i.e., they are angiogenic, pro-inflammatory, and immunostimulating (Soltes et al. 2007).

Degradation and depolymerization of HA can be performed by hyaluronidases or by physical ( $\gamma$-irradiation, thermal degradation) and chemical methods (acidic or alkaline hydrolysis) or by a deleterious action of free radicals (Stern et al. 2007).

A model of the HA degradation used in our experiment, is composed of ascorbate and $\mathrm{Cu}$ (II) ions (Figure 1.). The HA macromolecules demonstrate a really high sensitivity to the damaging action of ${ }^{\circ} \mathrm{OH}$ radicals generated according to the reaction:

$\mathrm{H}_{2} \mathrm{O}_{2}+\mathrm{Cu}(\mathrm{I}) / \mathrm{Fe}(\mathrm{II}) \rightarrow{ }^{\circ} \mathrm{OH}+\mathrm{Cu}(\mathrm{II}) / \mathrm{Fe}(\mathrm{III})+\mathrm{HO}^{-}$ The ${ }^{\circ} \mathrm{OH}$ radical, due to its extremely high reactivity, abstracts atomic hydrogen/hydrogen radical $\left(\mathrm{H}^{\bullet}\right)$ from the $\mathrm{HA}$ macromolecule forming a C-type macroradical which under aerobic conditions is reformed into a peroxyltype species participating in the propagation of the HA chain breaking (Rychly et al. 2006). 
Table 1. List of the natural curative water springs located at Bardejovske Kupele spa. (Source: http://www.kupele-bj.sk/lieciva_voda, 15.07.2013).

\begin{tabular}{|c|c|c|c|}
\hline $\begin{array}{c}\text { Natural } \\
\text { curative water } \\
\text { spring }\end{array}$ & $\begin{array}{l}\text { Chemical composition and } \\
\text { spring specification }\end{array}$ & $\begin{array}{c}\text { Treatment of specific } \\
\text { diseases }\end{array}$ & Therapeutic procedure \\
\hline Herkules & $\begin{array}{c}\mathrm{HCO}_{3}^{-}, \mathrm{Cl}^{-}, \mathrm{Na}^{+}, \mathrm{Fe}^{2+}, \mathrm{CO}_{2} \\
\text { hypotonic, cold }\end{array}$ & $\begin{array}{l}\text { diseases of the } \\
\text { stomach and } \\
\text { duodenum, } \\
\text { respiratory diseases, } \\
\text { diabetes }\end{array}$ & inhalation, drinking \\
\hline Hlavny & $\begin{array}{c}\mathrm{HCO}_{3}^{-}, \mathrm{Cl}^{-}, \mathrm{Na}^{+}, \mathrm{Fe}^{2+}, \mathrm{CO}_{2} \\
\text { hypotonic, cold }\end{array}$ & $\begin{array}{c}\text { diseases of the } \\
\text { stomach and } \\
\text { duodenum, a } \\
\text { condition after } \\
\text { stomach surgery, liver } \\
\text { diseases, the absence } \\
\text { of gastric juice, } \\
\text { disorders of blood } \\
\text { formation }\end{array}$ & drinking \\
\hline Lekarsky & $\begin{array}{c}\mathrm{HCO}_{3}^{-}, \mathrm{Cl}^{-}, \mathrm{Na}^{+}, \mathrm{Fe}^{2+}, \mathrm{CO}_{2} \\
\text { hypotonic, cold, alkaline } \\
\text { nature }\end{array}$ & $\begin{array}{c}\text { diseases of the } \\
\text { stomach and } \\
\text { duodenum, an excess } \\
\text { of gastric acid, } \\
\text { chronic bronchitis, } \\
\text { asthma }\end{array}$ & drinking \\
\hline Alzbeta & $\begin{array}{c}\mathrm{HCO}_{3}{ }^{-}, \mathrm{Cl}^{-}, \mathrm{Na}^{+}, \mathrm{Fe}^{2+}, \mathrm{CO}_{2}, \\
\text { traces of } \mathrm{H}_{2} \mathrm{~S} \\
\text { hypotonic, cold }\end{array}$ & liver diseases & drinking \\
\hline Klara & $\mathrm{Fe}^{2+}, \mathrm{CO}_{2}, \mathrm{H}_{2} \mathrm{~S}$ & $\begin{array}{l}\text { respiratory diseases, } \\
\text { rheumatic diseases of } \\
\text { the joints }\end{array}$ & $\begin{array}{l}\text { inhalation, drinking, } \\
\text { bathing }\end{array}$ \\
\hline Napoleon & $\begin{array}{l}\mathrm{HCO}_{3}^{-}, \mathrm{Cl}^{-}, \mathrm{Na}^{+}, \mathrm{Fe}^{2+}, \mathrm{CO}_{2}, \\
\text { increased content of } \mathrm{H}_{3} \mathrm{BO}_{3}\end{array}$ & $\begin{array}{l}\text { biliary tract diseases, } \\
\text { colitis diseases, } \\
\text { chronic liver diseases }\end{array}$ & drinking \\
\hline Anna & $\begin{array}{l}\mathrm{HCO}_{3}^{-}, \mathrm{Cl}^{-}, \mathrm{Na}^{+}, \text {increased } \\
\text { content of acid metabolites }\end{array}$ & $\begin{array}{l}\text { gastric dyspepsia, } \\
\text { chronic pancreatic } \\
\text { diseases, diseases of } \\
\text { upper respiratory tract }\end{array}$ & drinking \\
\hline
\end{tabular}




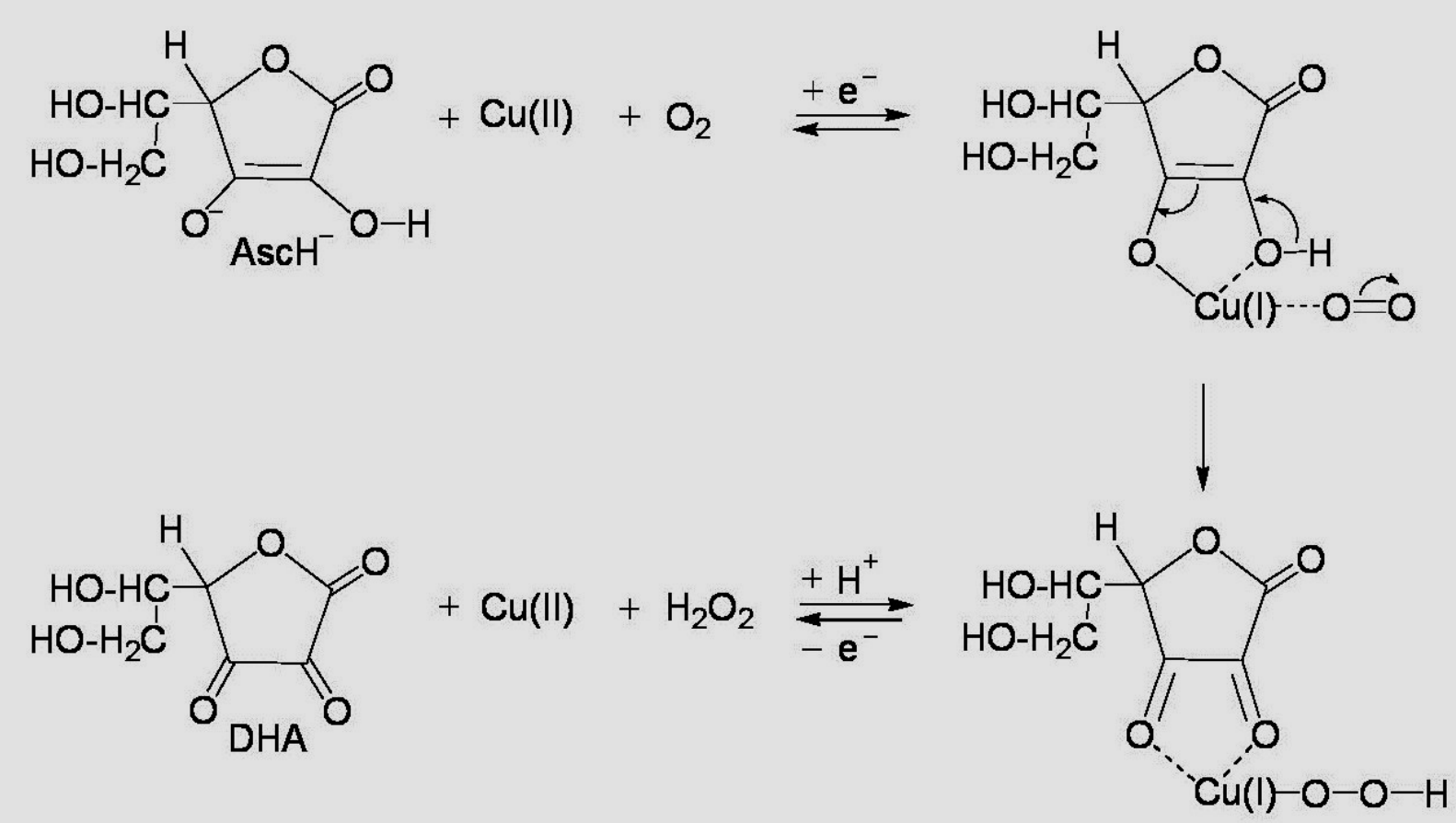

Figure 1. Mechanism of the action of Weissberger's biogenic oxidative system: Hydrogen peroxide is generated by oxidation of ascorbate under catalytic action of $\mathrm{Cu}$ (II) ions (adapted from Hrabarova E., Free-radical degradation of hyaluronan induced by reactive oxygen species. Evaluation of antioxidative properties of endogenous and exogenous substances containing a thiol group. PhD Thesis, Faculty of Chemical and Food Technology, Bratislava 2012, Slovakia, in Slovak). The same mechanism is expected in the case of $\mathrm{Fe}(\mathrm{III})$ when used instead of $\mathrm{Cu}(\mathrm{II})$.

Damaging action of reactive oxygen and nitrogen species (ROS and RNS) is connected with many human diseases. Rheumatoid arthritis and osteoarthritis are chronic, longterm inflammatory neurodegenerative diseases affecting mainly the synovial joints. ROS and RNS, among which just the ${ }^{\circ} \mathrm{OH}$ radical exhibits the most harmful effect, can contribute to the destruction or alteration of joint structures to such an extent that they are no longer functional. This situation results in the synovial fluid HA degradation (Darley-Usmar et al. 1995; Vilar et al. 1997).
The aim of our study was to investigate the potential protective effects of water-spa samples, namely the curative waters Alzbeta and Klara collected at Bardejovske Kupele-spa against degradation of high-molar-mass HA induced by ascorbate plus $\mathrm{Cu}$ (II) ions by the method of rotational viscometry. Among all of the spa waters mentioned in Table 1, Alzbeta and Klara have been chosen for their threshold natural iron concentrations; the highest one in "Alzbeta" (19.9 mg/L) and the lowest one in "Klara" (5.7 mg/L) as given by bel NOVAMANN ${ }^{\circledR} \quad$ International (Examination protocol No. 40474/2012: bel NOVAMANN ${ }^{\circledR}$ International eurofins, ilac-MRA, SNAS Reg. No. 031/S-106, L 1276). ABTS $^{\bullet+}$ radical cation scavenging capacity of the curative spa waters was investigated by a conventional ABTS assay. 


\section{Materials and methods}

\section{Chemicals}

High-molar-mass hyaluronan sample (sodium salt) coded P0207-1A was purchased from Lifecore Biomedical Inc., Chaska, MN, U.S.A. Analytical purity grade $\mathrm{NaCl}$ and $\mathrm{CuCl}_{2} \times 2 \mathrm{H}_{2} \mathrm{O}$ were purchased from Slavus Ltd., Bratislava, Slovakia. The thermal curative waters were withdrawn from the spa natural springs located at Bardejovske Kupele Inc.. LAscorbic acid and potassium persulfate $\left(\mathrm{K}_{2} \mathrm{~S}_{2} \mathrm{O}_{8}\right.$; p.a. purity, max. $0.001 \%$ nitrogen) was the product of Merck KGaA, Darmstadt, Germany. 2,2'-azinobis(3ethylbenzothiazoline-6-sulfonic acid) (ABTS; purum, >99\%) was from Fluka, Germany. Redistilled deionized high purity grade water with conductivity of $<0.055 \mu \mathrm{S} / \mathrm{cm}$ was produced using the TKA water purification system from Water Purification Systems GmbH, Niederelbert, Germany.

\section{Rotational viscometry}

Dynamic viscosity of the reaction mixture $(8 \mathrm{~mL} ; 0.15 \mathrm{M}$ aqueous $\mathrm{NaCl})$ containing HA $(20 \mathrm{mg})$, ascorbate $(100 \mu \mathrm{M})$ plus $\mathrm{Cu}(\mathrm{II})$ ions $(1 \mu \mathrm{M})$ in the absence and presence of curative spa waters Klara and Alzbeta (50 and $500 \mu \mathrm{l}$ ) was monitored by a Brookfield LVDV-II+PRO digital rotational viscometer (Brookfield Engineering Labs., Inc., Middleboro, MA, U.S.A.) at $25.0 \pm 0.1^{\circ} \mathrm{C}$ and at a shear rate of $237.6 \mathrm{~s}^{-1}$ for $5 \mathrm{~h}$ in the Teflon $^{\circledR}$ cup reservoir (Valachová et al. 2011). The curative spa water as potential protective agent was introduced into the reaction system at the beginning of the reaction or $1 \mathrm{~h}$ after the reaction onset.
The reason of the spa water addition within $1 \mathrm{~h}$ was the finding obtained by the EPR method that the delay of the HA degradation taking about $1 \mathrm{~h}$ can be explained by in situ formed hydrogen peroxide which may subsequently decompose intermediate product existing in the form of $\mathrm{Cu}(\mathrm{I})-\mathrm{AscH}^{-}$complex during initiation phase of radical chain reaction. This reaction stage is characterized by a preferential formation of ${ }^{\bullet} \mathrm{OH}$ radicals via the Fenton mechanism, however, as a consequence of the non-complexed ascorbate $\left(\mathrm{AscH}^{-}\right)$ excess, most of the ${ }^{\circ} \mathrm{OH}$ radicals are quenched by this anion forming stable anion ascorbyl radicals (Šoltés et al. 2006).

\section{ABTS assay}

Radical-scavenging activity was measured according to a modified ABTS method ( $R e$ et al. 1999). To prepare $\mathrm{ABTS}^{\bullet+}$ cation radical, an aq. soln. of $\mathrm{K}_{2} \mathrm{~S}_{2} \mathrm{O}_{8}(3.3 \mathrm{mg}$ of $\mathrm{K}_{2} \mathrm{~S}_{2} \mathrm{O}_{8}$ in $5 \mathrm{~mL}$ of $\mathrm{H}_{2} \mathrm{O}$ ) was added to ABTS (17.2 mg), and the resulting soln. was stored for $14 \mathrm{~h}$ in the dark. Finally, the darkgreen $\mathrm{ABTS}^{\bullet+}$ cation radical soln. (1 mL) was diluted with $\mathrm{H}_{2} \mathrm{O}(60 \mathrm{~mL})$ and used in the ABTS assays. The investigated samples comprised $2 \mathrm{~mL}$ of the diluted $\mathrm{ABTS}^{\bullet+}$ soln. with addition of $50 \mu \mathrm{L}$ of curative water Alzbeta or Klara, respectively. A modified ABTS assay was used applying a UV/VIS S2000 spectrophotometer (Sentronic, Germany) (Rychly et al. 2006; Rapta et al. 2009; Hrabarova et al. 2010), and UV/VIS spectra were recorded in 1,5 and 10-min intervals. 


\section{Results}

Figure 2, panel A illustrates the results of potential protective effects of the curative waters Klara and Alzbeta $(50 \mu \mathrm{L})$. A partial efficacy against the decrease of the HA solution $\eta$ can be observed, compared to the reference (black curve) represented by a prooxidative system \{ascorbate plus $\mathrm{Cu}(\mathrm{II})$ \}. The reference system caused $\eta$ drop from 11.5 to $6.22 \mathrm{mPa} \cdot \mathrm{s}$. The $\eta$ of the HA solution, when "Klara" was applied, decreased by $3.6 \mathrm{mPa} \cdot \mathrm{s}$ (red curve). However, more protective effect

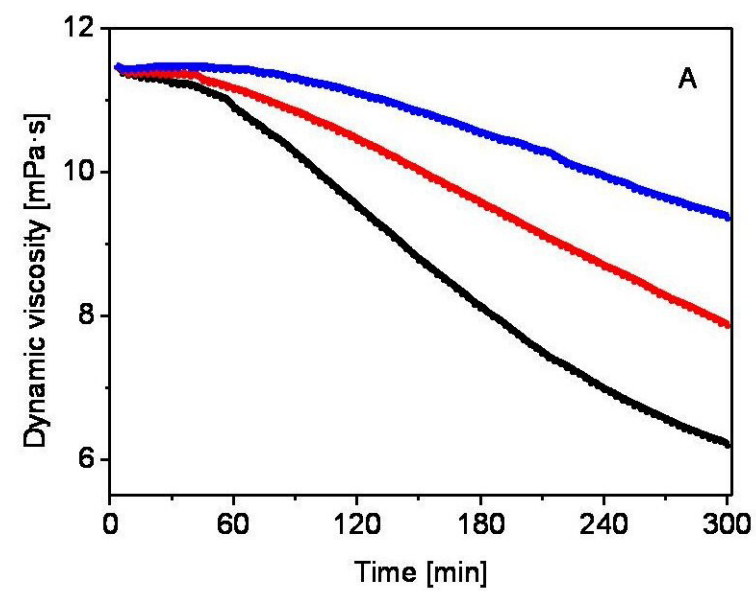

was observed in the case of "Alzbeta", where $\eta$ decreased from 11.5 to $9.38 \mathrm{mPa} \cdot \mathrm{s}$, i.e. it represents the decrease by $2.1 \mathrm{mPa} \cdot \mathrm{s}$.

The ten-fold higher volume bolus (500 $\mu \mathrm{L})$ led to the more protective effect against the oxidative HA degradation (Fig. 2, panel B): "Alzbeta" was observed to decrease the rate of the HA degradation more evidently compared to "Klara". The HA solution $\eta$ after a 5-h measurement was lower by 2.97 ("Klara") and $0.81 \mathrm{mPa} \cdot \mathrm{s}$ ("Alzbeta“).

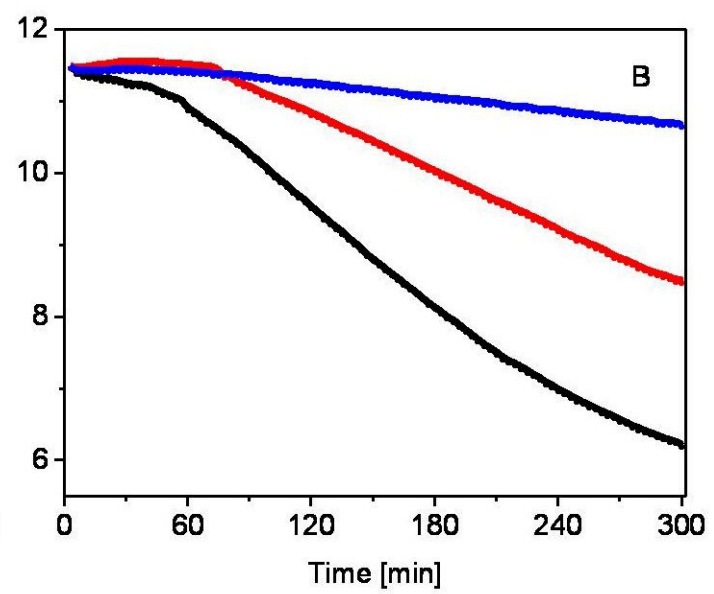

Figure 2. Effects of the curative spa waters Klara (red curve) and Alzbeta (blue curve) on the HA degradation induced by the oxidative system composed of $1.0 \mu \mathrm{M} \mathrm{CuCl}_{2}$ and $100 \mu \mathrm{M}$ ascorbate (black curve). Curative waters were added to the reaction system before initiation of the HA degradation in the volumes of 50 (panel A) and $500 \mu \mathrm{L}$ (panel B).
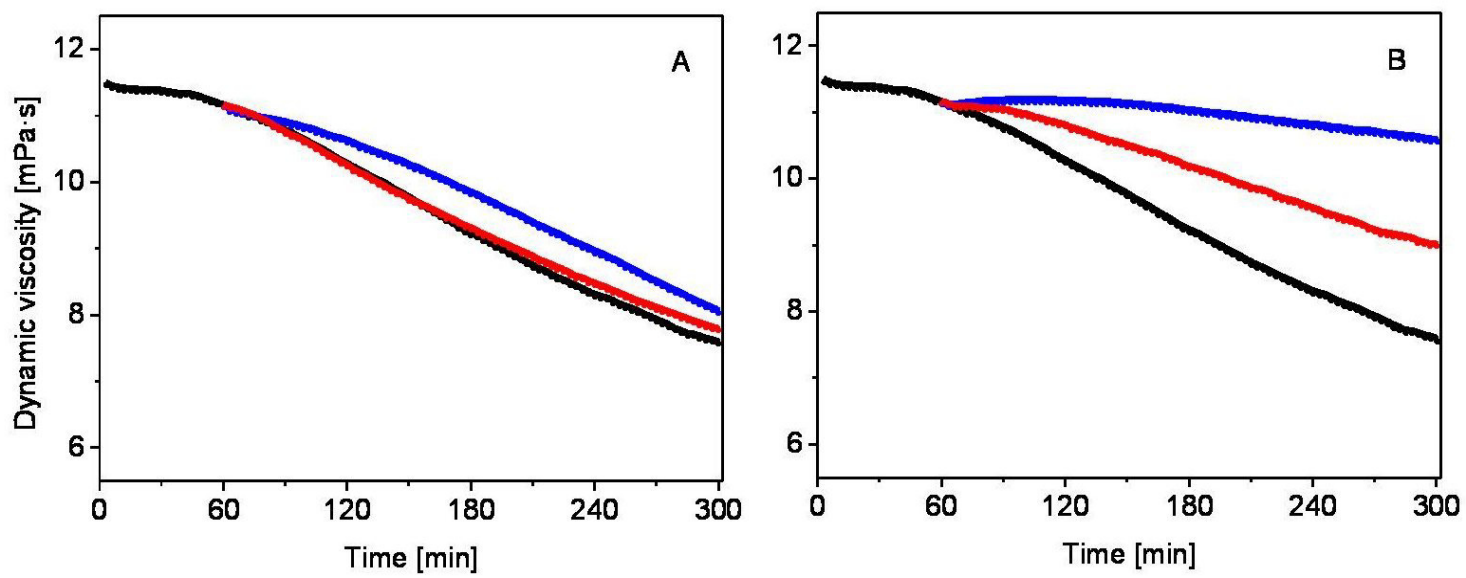

Figure 3. Effects of the curative spa waters Klara (red curve) and Alzbeta (blue curve) on the HA degradation induced by the oxidative system composed of $1.0 \mu \mathrm{M} \mathrm{CuCl}_{2}$ and $100 \mu \mathrm{M}$ ascorbate (black curve). Curative waters were added to the reaction system $1 \mathrm{~h}$ after initiating of the HA degradation in the volumes of 50 (panel A) and $500 \mu \mathrm{L}$ (panel B). 
Figure 3 represents the results of addition of the curative waters to the HA reaction system $1 \mathrm{~h}$ after initiation of the HA degradation. As seen, "Alzbeta" (panel A, blue curve) had a slightly higher protective effect against the HA degradation compared to "Klara" (panel A, red curve). Surprisingly, addition of $50 \mu \mathrm{L}$ of "Klara" to the HA reaction system led to almost the same course of the HA degradation than in the case of the reference (panel A, black curve). A higher volume of the curative waters, i.e. $500 \mu \mathrm{L}$ had a positive effect on decreasing the rate of the HA degradation, especially in the case of "Alzbeta" (panel B, blue curve). Unlike $50 \mu \mathrm{L}$ bolus addition of "Alzbeta" and "Klara" (Figure 2A and 3A), the effects of both waters applying the $500 \mu \mathrm{L}$ volume (Figure $2 \mathrm{~B}$ and 3B) were alike.
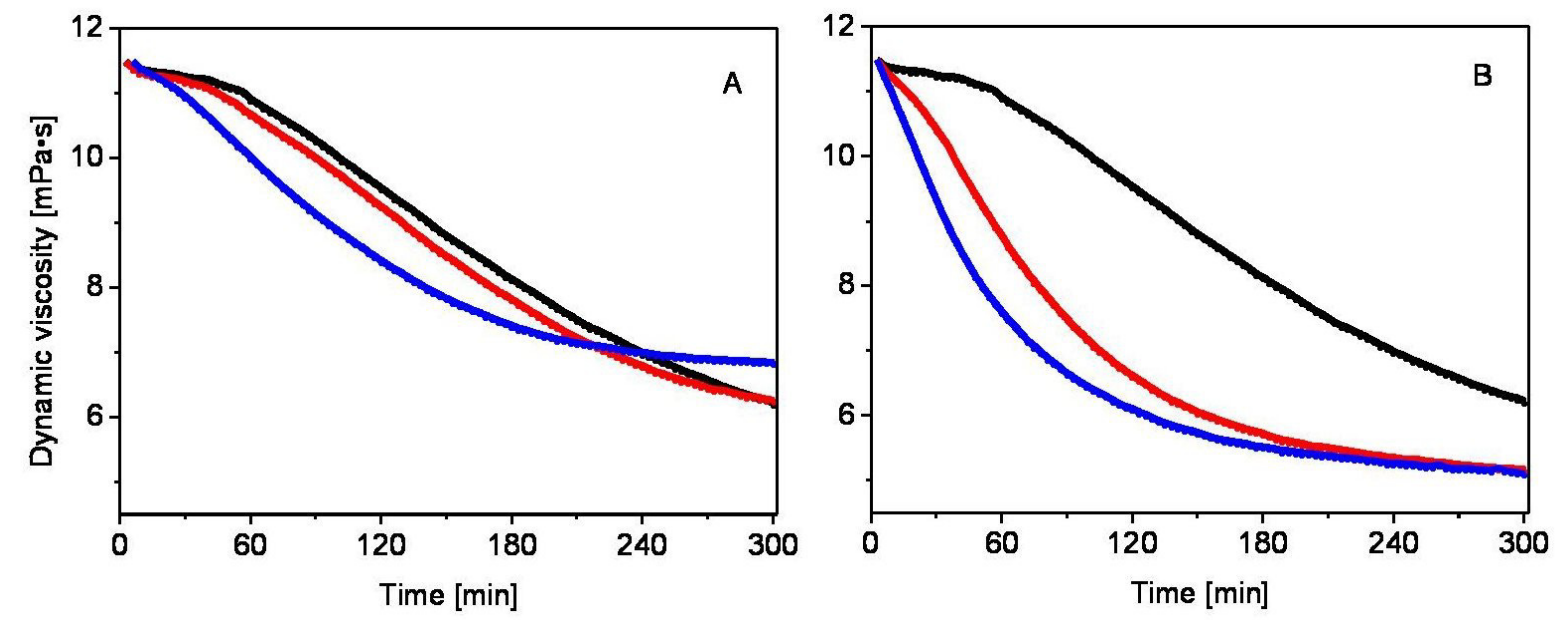

Figure 4. Effects of the $\mathrm{FeCl}_{3}$ solution on the $\mathrm{HA}$ degradation induced by the oxidative system composed of $1.0 \mu \mathrm{M} \mathrm{CuCl}$ and $100 \mu \mathrm{M}$ ascorbate (black curve). Solutions of $\mathrm{FeCl}_{3}$ were added to the reaction system before initiation of the $\mathrm{HA}$ degradation in the volumes of 50 (panel A) and $500 \mu \mathrm{L}$ (panel B). The $\mathrm{FeCl}_{3}$ concentrations corresponded to the concentrations of total iron present in the curative waters Klara (red curve) and Alzbeta (blue curve).

Due to the presence of natural iron in the curative waters - present either in elementary form or in the form of ferric/ferrous ions - we examined also the influence of ferric chloride alone on the HA degradation before the reaction onset. The $\mathrm{FeCl}_{3}$ concentrations corresponded to the concentrations of iron in the Klara and Alzbeta curative waters. As seen in Fig. 4, panel A, red curve, almost identical degradative action was observed after addition of a $50 \mu \mathrm{L} \mathrm{FeCl}_{3}$ solution as in the case of the reference. On the other hand, the addition of a $50 \mu \mathrm{L} \mathrm{FeCl}_{3}$ solution, $\eta$ of the HA solution decreased remarkably within the $3^{\text {rd }} \mathrm{h}$ (blue curve). As illustrated in Fig. 4, panel B, the increase of the volume of $\mathrm{FeCl}_{3}$ solution up to $500 \mu \mathrm{L}$ brought about a more intensive HA degradation in both cases since very beginning, however to a less extent in the case of "Klara"simulating $\mathrm{FeCl}_{3}$ addition. 

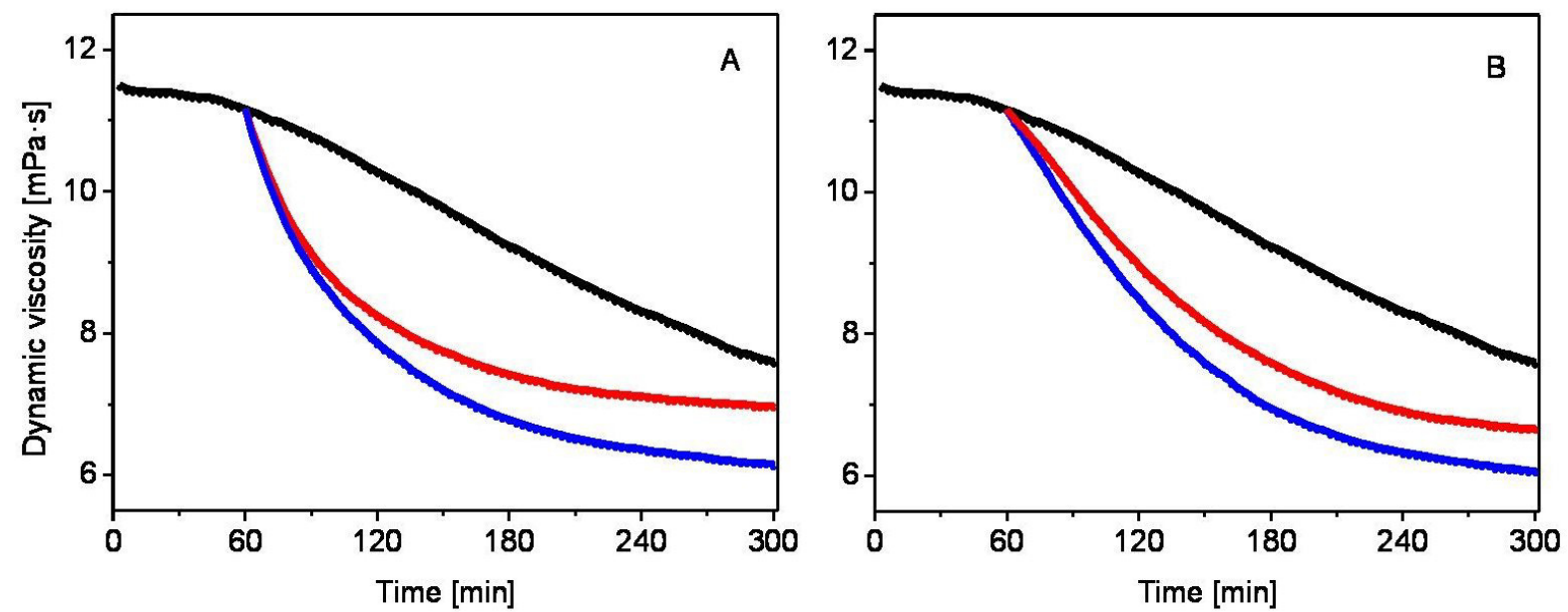

Figure 5. Effects of the $\mathrm{FeCl}_{3}$ solution on the $\mathrm{HA}$ degradation induced by the oxidative system composed of $1.0 \mu \mathrm{M} \mathrm{CuCl}$ and $100 \mu \mathrm{M}$ ascorbate (black curve). Solutions of $\mathrm{FeCl}_{3}$ were added to the reaction system $1 \mathrm{~h}$ after initiation of the $\mathrm{HA}$ degradation in the volumes of 50 (panel A) and $500 \mu \mathrm{L}$ (panel B). The $\mathrm{FeCl}_{3}$ concentrations corresponded to the concentrations of total iron present in the curative waters Klara (red curve) and Alzbeta (blue curve).

As shown in Figure 5, panel A, a $50 \mu \mathrm{L}$ addition of the "Alzbeta"-simulating $\mathrm{FeCl}_{3}$ solution (blue curve) $1 \mathrm{~h}$ after the reaction onset led to a more increased rate of the HA degradation compared to the application of the same volume of the "Klara"-simulating $\mathrm{FeCl}_{3}$ addition. The $\mathrm{FeCl}_{3}$ concentrations

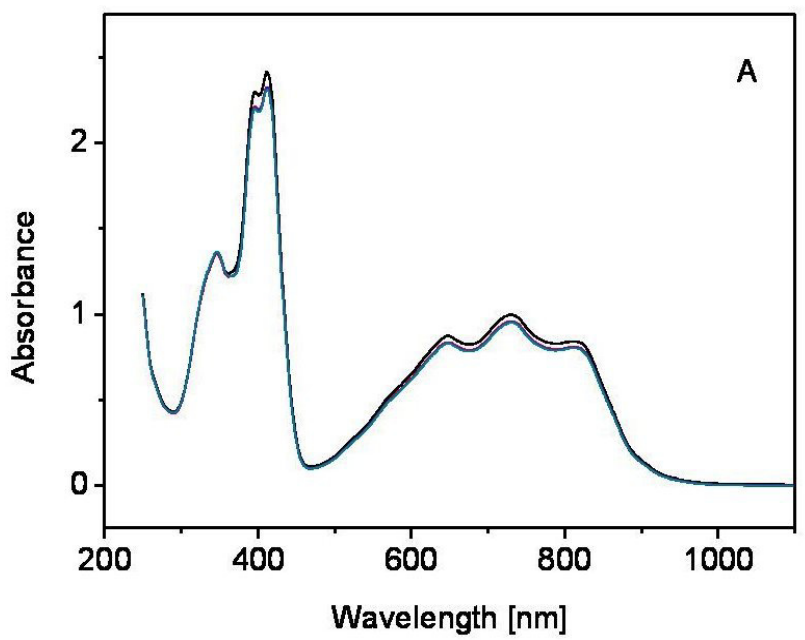

corresponded to the concentrations of iron in the Klara and Alzbeta curative waters. The same effect was observed (Fig. 5, panel B) on applying a higher volume of the $\mathrm{FeCl}_{3}$ solution $(500 \mu \mathrm{L})$, however the degradative effect was less intensive than in the case of a $50 \mu \mathrm{L}$ addition.

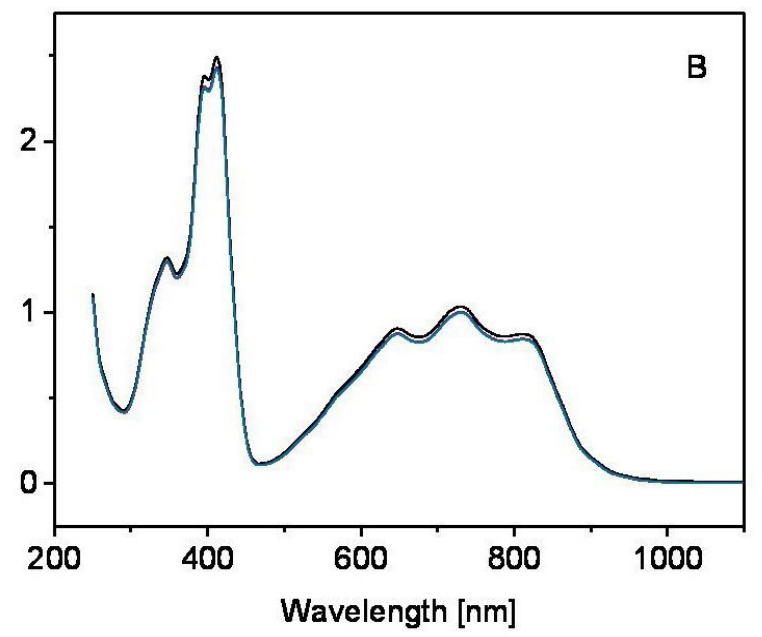

Figure 6. Effects of the $\mathrm{ABTS}^{*+}$ cation radical scavenge by the curative waters Klara (panel A) and Alzbeta (panel B): the 1 st $\min$ (red line), the 5 th $\min$ (blue line), and the 10th $\min$ (green line). The spectrum of the ABTS $^{\circ+}$ cation radical alone (black line). 


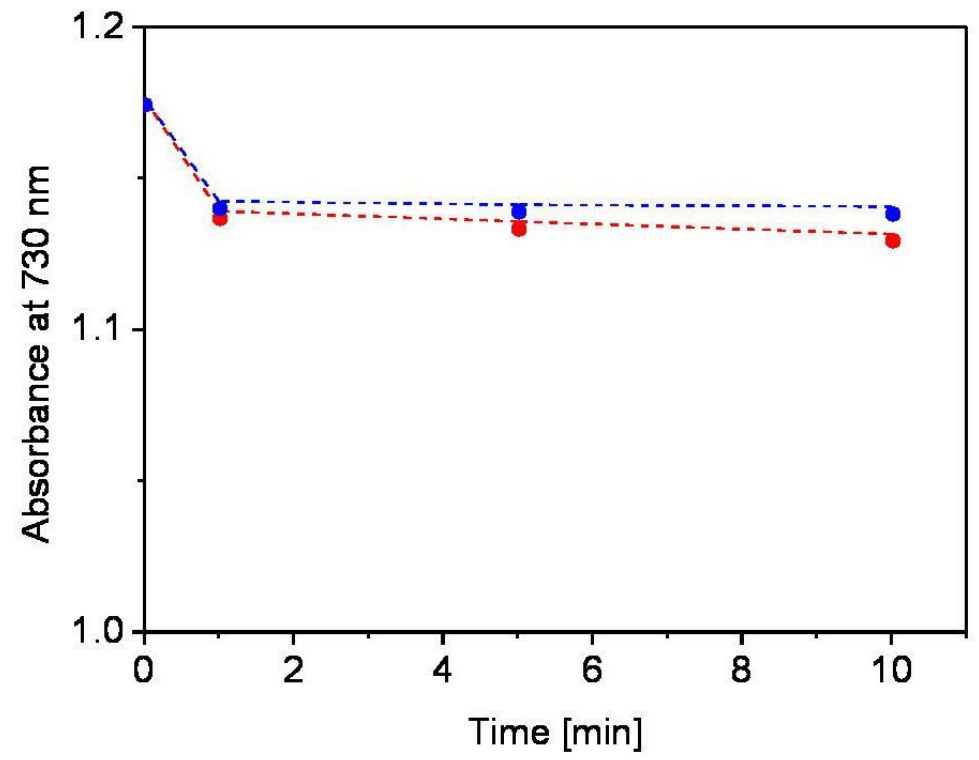

Figure 7. The detailed depiction of the time-dependent suppression of the $\mathrm{ABTS}^{-+}$cation radical absorbance at the preferential wavelength $(730 \mathrm{~nm}$ ) measured after the addition of the curative waters Klara (red curve) and Alzbeta (blue curve) into the $\mathrm{ABTS}^{\circ+}$ solution.

To support the results achieved by the study of the oxidative HA degradation measured by rotational viscometry, the wellestablished standard ABTS decolorization method was applied. The ABTS assays of both curative waters showed almost no ABTS $^{\bullet+}$ cation radical scavenging capacity (Fig. 6) as a consequence of low electron donating properties of the samples tested. Figure 7 displays the time-dependent suppression of the $\mathrm{ABTS}^{\circ+}$ cation radical absorbance by the both curative waters confirming their low efficacy.
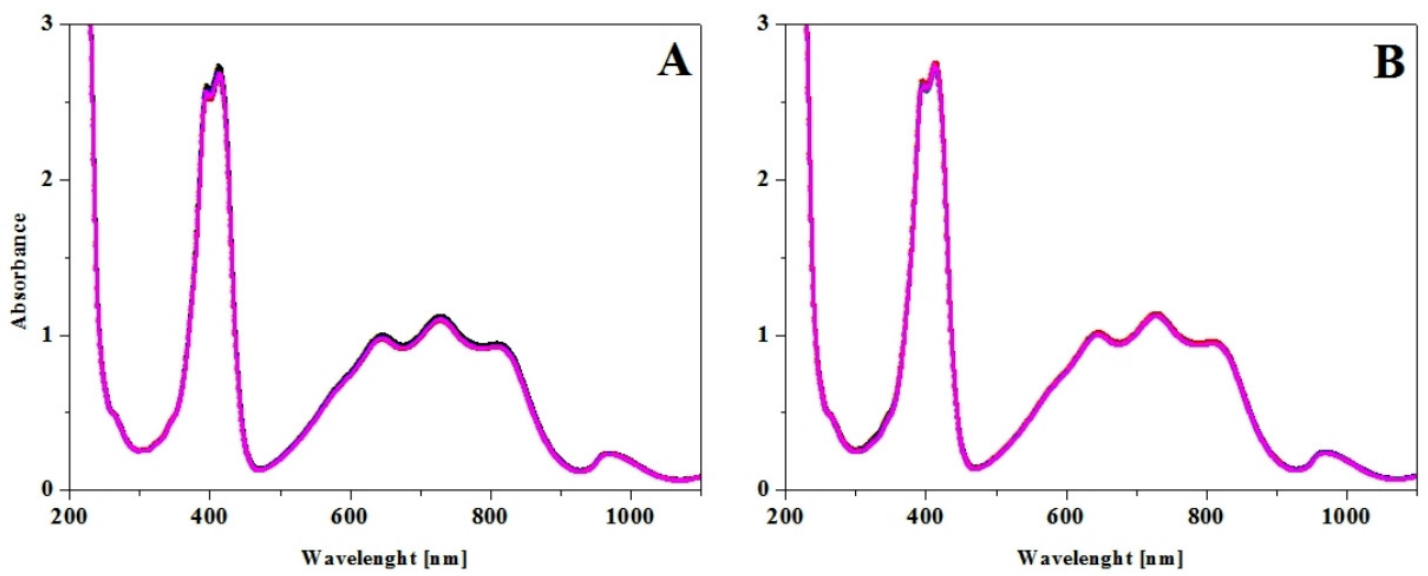

Figure 8. Effects of the $\mathrm{ABTS}^{*+}$ cation radical scavenge by the $\mathrm{FeCl}_{3}$ solutions. The $\mathrm{FeCl}_{3}$ concentrations corresponded to the concentrations of total iron present in the curative waters Alzbeta (panel A) and Klara (panel B): 1st min (red line), the 5 th min (blue line), and the 10th min (pink line). The spectrum of the $\mathrm{ABTS}^{\circ+}$ cation radical alone (black line). 


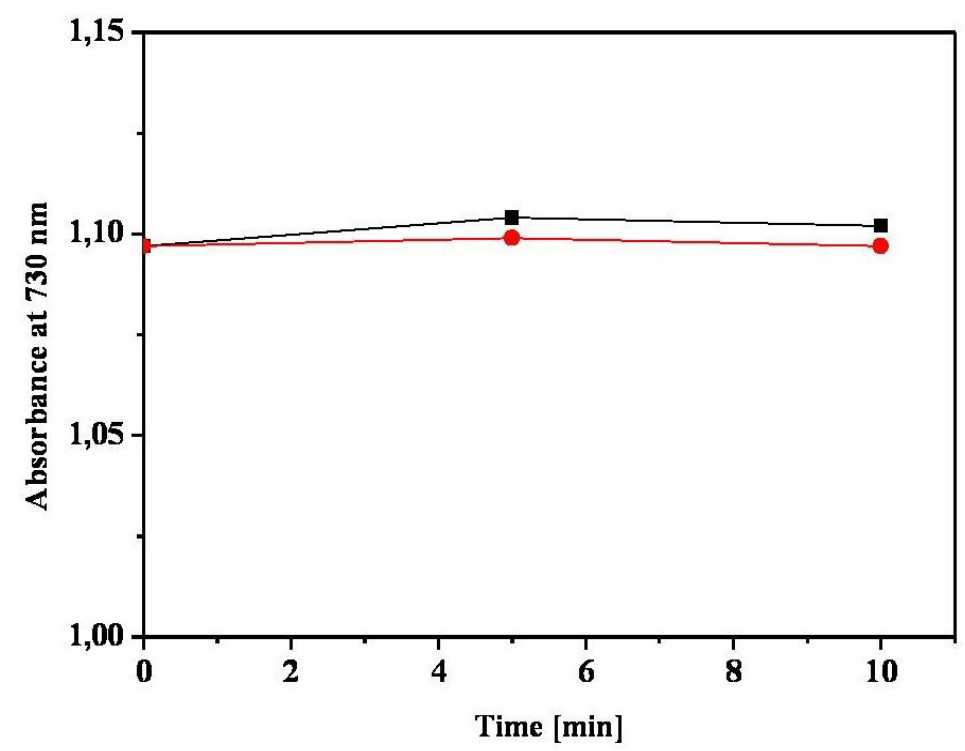

Figure 9. The detailed depiction of the time-dependent suppression of the $\mathrm{ABTS}^{\bullet+}$ cation radical absorbance at the preferential wavelength $(730 \mathrm{~nm})$ measured after the addition of the $\mathrm{FeCl}_{3}$ solutions. $\mathrm{The} \mathrm{FeCl}_{3}$ concentrations corresponded to the concentrations of total iron present in the curative waters Alzbeta (black line) and Klara (red line).

For comparison ABTS decolorization method was also applied on $\mathrm{FeCl}_{3}$ solutions. The ABTS assays of both The $\mathrm{FeCl}_{3}$ concentrations, which corresponded to the concentrations of total iron present in the curative waters Alzbeta and Klara showed no $\mathrm{ABTS}^{\bullet+}$ cation radical scavenging capacity (Fig. 8) as a consequence of low electron donating properties of the samples tested. Figure 9 displays the time-dependent suppression of the $\mathrm{ABTS}^{\circ+}$ cation radical absorbance by the both $\mathrm{FeCl}_{3}$ solutions, confirming their low efficacy.

\section{Discussion}

Our work was accomplished in continuation to our previous research monitoring the same idea - competition between pro-degradative and protective effects of the curative Piešt'any-spa waters from healing peloid and maturation pool in order to test HA against degradation (Hrabarova et al. 2012).

Due to the multi-component character of the spa waters Klara and Alzbeta, various multi-functional effects may be expected.
Individual natural components may interact each other in some way influencing thus resultant water behavior. Except for iron alone, the presence of natural $\mathrm{Fe}$ (II) ions in the spa waters $-<0.1 \mathrm{mg} / \mathrm{L}$ in Klara and $7.0 \mathrm{mg} / \mathrm{L}$ in Alzbeta (Table 2) may be also expected to contribute to the production of hydrogen peroxide by the Fenton mechanism or can degrade ascorbate The expected prodegradative effect of transition metal couple $\mathrm{Fe}(\mathrm{II}) / \mathrm{Fe}$ (III) is probably outbalanced by potential natural chelators of transition metals as evidenced by their protective effect against the HA degradation. Since the samples of curative waters contain wide range of native compounds and elements, the experiments performed should be classified as a "black box" study.

In the previous years, numerous studies have documented the role of ROS in the etiology and pathogenesis of osteoarthritis. In accordance with literature, in osteoarthritis there is a close relationship between oxidative stress, inflammation and cartilage degeneration. 
The curative spa waters and iron solutions were tested in the already-running HA degradation. During the 1-hour propagation phase, HA macromolecules are degraded via free-radical chain-breaking processes. This phase can thus be classified as one of the most destructive. According to the gradual exhaustion of the ascorbate the nonquenched hydroxyl radicals can react with the HA macromolecule (Hrabarova et al. 2010). Under aerobic conditions, the alkyl-type macroradical $\left(\mathrm{A}^{\bullet}\right)$ reacts rapidly with dioxygen $\left(\mathrm{O}_{2}\right)$ forming a peroxyl-type macroradical $\left(\mathrm{AOO}^{\bullet}\right)$. The intermediate peroxyl-type macroradical may react with an nearby HA rnacromolecule, and thus the radical chain reaction propagates quickly (Valachova et al. 2012)

The greater the volume of the spa-water the greater was the antioxidative effect. The observed retardation of the $\eta$ value drop as a result of the antioxidative effect of the curative spa water samples. "Alzbeta" appears to be more effective in maintaining of dynamic viscosity of the HA solution compared to "Klara".
The addition of ferric ions expressed significant decrease of dynamic viscosity of the HA solutions.

We can conclude the ABTS decolorization method was not a supportive one to test potential protective properties of the curative waters Klara and Alzbeta as a result of high iron content. It can be really expected that iron during reaction formed chelate structures with the $\mathrm{ABTS}^{\circ+}$ cation radical, and by that the suppression of the $\mathrm{ABTS}^{\circ+}$ cation radical absorbance was restrained via formed $\mathrm{ABTS}^{\bullet+} /$ iron complex. Such a system was thus unable to acquire its neutral form receiving electron. Therefore, the reaction rate of the spa water/ABTS ${ }^{\bullet+}$ cation radical was assumed to be significantly reduced as a consequence of the complexation (Dawidowicz et al. 2011).

Recent studies suggest that hydrogen sulfide exhibits potential antioxidative capacity and improves vascular and tissue functions, and is therefore regarded as an important candidate in medicine as a therapeutic gas ( $\mathrm{Yu}$ et al. 2011). Because this species is present in the both waters (Table 2), partial contribution to the deactivation of radical formations during the HA degradation is very probable.

Table 2. Sulfur-based compounds and transition metals in the curative spa waters Alzbeta and Klara.

\begin{tabular}{|c|c|c|}
\hline & Alzbeta & Klara \\
\cline { 2 - 3 } & Concentration $[\mathrm{mg} / \mathrm{mL}]$ & Concentration $[\mathrm{mg} / \mathrm{mL}]$ \\
\hline Free sulfide (hydrogen sulfide) & $<0.005$ & 1.09 \\
\hline Sulfides & $<0.03$ & 1.4 \\
\hline Hydrosulfide & $<0.03$ & 0.31 \\
\hline Sulfate & 8.34 & 35.4 \\
\hline Copper & $<0.003$ & 0.014 \\
\hline Iron & 19.9 & 5.7 \\
\hline $\mathrm{Fe}^{2+}$ & 7.0 & $<0.1$ \\
\hline
\end{tabular}


One can assume the iron content as well as the content of other transition metals in the spa waters is not a decisive generalized factor to evaluate their protective effect. It means, for example, two natural waters with the same content of iron, copper, and other transition metals may exhibit various protective effects determined by the different content and structure of other potential, either of the same or any other structure, natural chelators. That is why it could be desirable to perform the tests of all the spa waters (Table 1) to make more broad and specific comparison.

Study of potential protective effects of the Bardejovske Kupele spa curative waters against the HA oxidative destabilization in the synovial joints leading to inflammatory conditions and pain development is expected to have considerable impact on society in point of the treatment of the locomotive system of humans. Moreover, the study like ours as well as many others may be, from the viewpoint of the next progress of the Bardejovske Kupele spa, very conducive.

The spa curative waters may be considered as prospective compounds in preventing of oxidative HA degradation.

Acknowledgements: The work was supported by the grants VEGA 2/0011/11, 2/0149/12, 2/0136/13, and APVV 0351-10.

The authors wish to express their thanks to the Director of Health Spa Bardejovske Kupele, Inc., Dipl-Eng. Dr. Jaroslav Komora for his kind approval of the research realization.

\section{References}

Albertini M. C., Dachà M., (2007): Drinking Mineral Waters: Biochemical Effects and Health Implications - the State-of-the-art. International Journal of Environment and Health 1, 153-169
Dawidowitz A. L. and Olszowy M. (2011): Antioxidant properties of BHT estimated by ABTS assay in systems differing in $\mathrm{pH}$ or metal ion or water concentration. Eur Food Res Technol 232, 837-842

Hrabárová E., Valachová K., Rapta P., Śltés L. (2010): An Alternative Standard for Trolox-Equivalent Antioxidant-Capacity Estimation Based on Thiol Antioxidants. Comparative 2,2'-Azinobis[3ethylbenzothiazoline-6-sulfonic Acid] Decolorization and Rotational Viscometry Study Regarding Hyaluronan Degradation. Chem. Biodiversity 7, 2191

Hrabárová E, Valachová K, Juránek I, Šoltés L: Free-radical degradation of highmolar-mass hyaluronan induced by ascorbate plus cupric ions. Anti-oxidative properties of the Piešt'any-spa curative waters from healing peloid and maturation pool. In Chapter in the book „Kinetics, Catalysis and Mechanism of Chemical Reactions“, Eds. Pethrick RA, Petkov P, Zlatarov A, Zaikov GE, Rakovsky SK: Polymer Yearbook Vol. 25, Nova Science Publishers, New York, USA. ISBN: 978-161470-712-7, (2012), pp. 29-36.

Hrabarova E., Free-radical degradation of hyaluronan induced by reactive oxygen species. Evaluation of antioxidative properties of endogenous and exogenous substances containing a thiol group. $\mathrm{PhD}$ Thesis, Faculty of Chemical and Food Technology, Bratislava 2012, Slovakia. (in Slovak)

Matz H., Orion E., Wolf R. (2003): Balneotherapy in dermatology. Derm. Therapy 16, 132-140

Nasermoaddeli A., Kagamimor S. (2005): Balneotherapy in Medicine: A Review. Environmental Health and Preventive Medicine 10, 171-179

Rapta P., Valachová K., Gemeiner P., Šoltés L. (2009): High-Molar-Mass Hyaluronan Behavior During Testing Its 
Radical Scavenging Capacity in Organic and Aqueous Media: Effects of the Presence of Manganese(II) IonsChem. Biodiversity 6, 162.

Re R., Pellegrini N., Proteggente A., Pannala A., Yang M., Rice-Evans C. (1999): Antioxidant activity applying an improved ABTS radical cation decolorization assay. Free Radical Biol. Med. 26, 1231

Rychlý J., Šoltés L., Stankovská M., Janigová I., Csomorová K., Sasinková V., et al. (2006): Unexplored capabilities of chemiluminescence and thermoanalytical methods in characterization of intact and degraded hyaluronans. Polym Degrad Stab. 91, 3174-3184

Soltes L., Kogan G., Stankovska M., Mendichi O. R., Rychly J., Schiller J., Gemeiner P. (2007): Degradation of HighMolar-Mass Hyaluronan and Characterization of Fragments. Biomacromolecules 8, 2697 2705

Soltes L., Brezova V., Stankovska M., Kogan G., Gemeiner P. (2006): Degradation of high-molecular-weight hyaluronan by hydrogen peroxide in the presence of cupric ions. Carbohydr Res 341, 639-644

Stern R., Kogan G., Jedrzejas M. J., Šoltés L. (2007): The many ways to cleave hyaluronan. Biotechnology Advances 25, 537557
Tubergen A van, Linden S van der (2002): A brief history of spa therapy. Ann Rheum Dis 61, 273-275

Vilar R., Ghael D., Li M., Bhagat D.D., Arrigo L.M., Cowman M.K., Dweck H.S., Rosenfeld L. (1997): Nitric Oxide Degradation of Heparin and Heparan Sulfate. Biochem J $324,473-479$

Valachová K., Vargová A., Rapta P., Hrabárová E., Dráfi F., Bauerová K., Juránek I., Šoltés L. (2011): Aurothiomalate as preventive and chain-breaking antioxidant in radical degradation of high-molar-mass hyaluronan. Chem Biodivers 7, 1274-1283

Yu Y.-P., Li Z.-G., Wang D.-Z., Zhan X., Shao J.-H. (2011): Hydrogen sulfide as an effective and specific novel therapy for acute carbon monoxide poisoning. Biochem Biophys Res Commun 404, 6-9

Examination protocol No. 40474/2012: bel NOVAMANN ${ }^{\circledR} \quad$ International eurofins, ilacMRA, SNAS Reg. No. 031/S-106, L 1276. 